\title{
Reactions with 2-Acylbenzimidazole \\ Preparation of 2-Cinnamoylbenzimidazoles, their Reactions towards Grignard Reagents and Thiourea
}

\author{
Mohamed I. Ali, Abd-Elsamei M. Abd-Elfattah, and Hamdy A. Hammouda \\ Chemistry Department, Faculty of Science, Cairo University, Egypt
}

(Z. Naturforsch. 31 b, 254-256 [1976]; received September 22, 1975)

2-Acylbenzimidazole, 2-Cinnamoylbenzimidazoles, Grignard Reagents, Benzimidazolylpyrimidine

2-Acetylbenzimidazole condensed with aldehydes to afford the 2-cinnamoyl derivatives (1a-e). Whereas 2-acetyl- and 2-benzoylbenzimidazole added Grignard reagents at the carbonyl group, the 2-cinnamoyl derivatives $(\mathbf{1} \mathbf{a}, \mathbf{b})$ suffered addition at the olefinic double bond to give $\mathbf{2 a , b}$. Condensation of amines with 2 -acetyl and 2-benzoylbenzimidazole yielded the imino compounds $(\mathbf{4} \mathbf{a}-\mathbf{c}) .1$ a reacted with thiourea to furnish the pyrimidine (5).

The presence of a benzimidazole moiety in various biologically active drugs led us as many other investigators ${ }^{1-6}$ to synthesize and study the properties of new benzimidazole derivatives.

2-Acetylbenzimidazole ${ }^{7}$ condensed with aromatic aldehydes in boiling ethanol in the presence of fused sodium acetate to give 2 -cinnamoylbenzimidazoles $(\mathbf{1} \mathbf{a}-\mathbf{e})$.

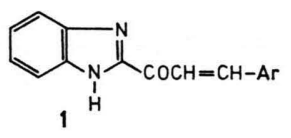
a) $\mathrm{Ar}=\mathrm{C}_{6} \mathrm{H}_{5}$,
b) $\mathrm{Ar}=\mathrm{C}_{6} \mathrm{H}_{4} \mathrm{OCH}_{3}-p$,
c) $\mathrm{Ar}=\mathrm{C}_{6} \mathrm{H}_{4} \mathrm{Cl}-p$,
d) $\mathrm{Ar}=\mathrm{C}_{6} \mathrm{H}_{4} \mathrm{NO}_{2}-p$,
e) $\mathrm{Ar}=\mathrm{C}_{6} \mathrm{H}_{4} \mathrm{~N}\left(\mathrm{CH}_{3}\right)_{2}-p$.

The IR spectrum of 1 a shows NH absorption at $3320 \mathrm{~cm}^{-1}$ and $\mathrm{CO}$ absorption at $1695 \mathrm{~cm}^{-1}$, with almost no significant shift from the $\mathrm{CO}$ absorption of the acetyl compound $\left(1685 \mathrm{~cm}^{-1}\right)$.

The absorption of the cinnamoyl carbonyl at an apparent high wave number may be attributed to that the acetyl compound exhibits a higher degree of intramolecular hydrogen bonding ${ }^{8}$.

The addition of Grignard reagents to the cinnamoyl derivatives $(\mathbf{1} \mathbf{a}, \mathbf{b})$ afforded the 2-(3,3-diarylpropanoyl)benzimidazoles $(\mathbf{2} \mathbf{a}, \mathbf{b})$.

Requests for reprints should be sent to Dr. H. A. Hammouda, Chemistry Department, Faculty of Science, Cairo University, Giza, A.R. Egypt.

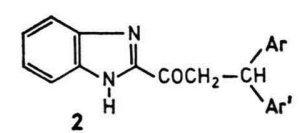

a) $\mathrm{Ar}=\mathrm{Ar}^{\prime}=\mathrm{C}_{6} \mathrm{H}_{5}$,

b) $\mathrm{Ar}=\mathrm{C}_{6} \mathrm{H}_{5} ; \mathrm{Ar}^{\prime}=\mathrm{C}_{6} \mathrm{H}_{4} \mathrm{OCH}_{3}-p$.

The structures assigned to the products $(\mathbf{2 a}, \mathbf{b})$ were based on the following facts:

a) Unlike the cinnamoyl derivatives, these products are colourless, and they give the correct analytical values,

b) the absence of an $\mathrm{OH}$ group and the presence of a carbonyl group as revealed from the IR spectrum of $2 \mathrm{a}$, taken as example, $v \mathrm{CO} ; 1695 \mathrm{~cm}^{-1}$,

c) the formation of the same product $\mathbf{2} \mathbf{b}$ either from $p$-methoxyphenylmagnesium bromide and 1a, or from phenylmagnesium bromide and $\mathbf{1 b}$.

This conforms with the conjugate addition of Grignard reagents cited in literature ${ }^{9,10}$.

On the other hand, Grignard reagents added to the carbonyl group in 2-acetylbenzimidazole and 2 -benzoylbenzimidazole ${ }^{11}$ with the formation of the carbinols (3a-e).

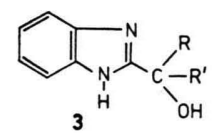

a) $\mathrm{R}=\mathrm{R}^{\prime}=\mathrm{CH}_{3}$,

b) $\mathrm{R}=\mathrm{CH}_{3} ; \mathrm{R}^{\prime}=\mathrm{C}_{2} \mathrm{H}_{5}$,

c) $\mathrm{R}=\mathrm{CH}_{3} ; \mathrm{R}^{\prime}=\mathrm{C}_{6} \mathrm{H}_{5}$,

d) $\mathrm{R}=\mathrm{R}^{\prime}=\mathrm{C}_{6} \mathrm{H}_{5}$,

e) $\mathrm{R}=\mathrm{C}_{6} \mathrm{H}_{5} ; \mathrm{R}^{\prime}=\mathrm{C}_{6} \mathrm{H}_{4} \mathrm{CH}_{3}-\mathrm{o}$. 
The IR spectra of 3a-c show absorption bands at $3400 \mathrm{~cm}^{-1}(\mathrm{OH})$ and at $3320 \mathrm{~cm}^{-1}(\mathrm{NH})$.

Furthermore, that the addition of phenylmagnesium bromide to the 2 -acetylbenzimidazole led to the formation of the same compound $(\mathbf{3 c})$ obtained from the 2-benzoylbenzimidazole and methylmagnesium iodide, is in favour of the structure 3 .

2-Acetyl and 2-benzoylbenzimidazoles condensed with aniline and $p$-toluidine at $140{ }^{\circ} \mathrm{C}$ to afford the corresponding imino derivatives $(4 \mathbf{a}-\mathbf{c})$.

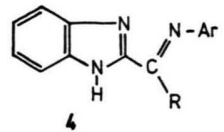

a) $\mathrm{R}=\mathrm{CH}_{3} ; \mathrm{Ar}=\mathrm{C}_{6} \mathrm{H}_{5}$,

b) $\mathrm{R}=\mathrm{Ar}=\mathrm{C}_{6} \mathrm{H}_{5}$,

c) $\mathrm{R}=\mathrm{C}_{6} \mathrm{H}_{5} ; \mathrm{Ar}=\mathrm{C}_{6} \mathrm{H}_{4} \mathrm{CH}_{3}-p$.

The structure of compounds 4 a-c was inferred from their analytical data and from the absence of carbonyl absorption in the IR spectra of compounds $4 \mathbf{a}, \mathbf{b}$.

$\alpha, \beta$-Unsaturated ketones react with thiourea to give 2-thiopyrimidine derivatives ${ }^{12-14}$. Thus, when the 2-cinnamoyl derivative (1a) was heated with thiourea in boiling ethanol in the presence of potassium hydroxide, it gave 5,6-dihydro-4(2benzimidazolyl)-6-phenyl-2 $(1 \mathrm{H})$-pyrimidinethione (5).

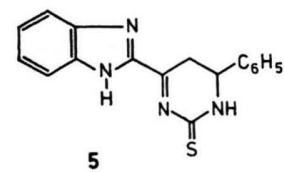

The structure of compound $\mathbf{5}$ was established from its analytical data and from the consideration of its IR spectrum whereas no absorption appeared at the $\mathrm{C}=\mathrm{O}$ region nor at the $\mathrm{SH}$ region; there is only one band at $3330 \mathrm{~cm}^{-1}$ assigned to an $\mathrm{NH}$ group.

\section{Experimental}

Melting points are not corrected. IR spectra were recorded on a Carl Zeiss Infracord Spectrophotometer "UR 10".

\section{Preparation of 2-cinnamoylbenzimidazoles (1a-e) General procedure}

A mixture of 2-acetylbenzimidazole $\quad(1.6 \mathrm{~g}$; 0.01 mole), fused sodium acetate $(3 \mathrm{~g})$ and 0.01 mole of the appropriate aromatic aldehyde was refluxed in $30 \mathrm{ml}$ of ethanol for 3 hours. The reaction mixture was then cooled and poured into cold water, the precipitate that formed was collected, washed with water and crystallized from the proper solvent (cf. Table I).

The derivatives 1a-e are yellow to orange in colour but they all give blood-red colour with concentrated sulphuric acid.

\section{Action of Grignard reagents on $\mathbf{1} \mathbf{a}, \mathbf{b}$}

To an ethereal solution of phenylmagnesium bromide (obtained from $1 \mathrm{~g}$ of magnesium metal and $9 \mathrm{~g}$ of bromobenzene in ca. $50 \mathrm{ml}$ of dry ether) was added $2 \mathrm{~g}$ of $1 \mathrm{a}$ or $1 \mathrm{~b}$ dissolved in $c a .50 \mathrm{ml}$ of dry ether. The reaction mixture was gently heated on a water bath using a calcium chloride tube for $45 \mathrm{~min}$. After cooling it was hydrolyzed by a saturated ammonium chloride solution (ca. $300 \mathrm{ml}$ ) and extracted with ether. The ethereal layer, after drying over anhydrous sodium sulphate, was allowed to evaporate. The oily residue left behind was triturated with petroleum ether. The solid, so obtained, was collected and crystallized. 1a gave 2a, crystallized from ethanol, m.p. $214^{\circ} \mathrm{C}$; yield $71 \%$.

Analysis: $\mathrm{C}_{22} \mathrm{H}_{18} \mathrm{~N}_{2} \mathrm{O}$

Calcd C 80.94 H 5.57 N 8.58,

Found C 80.81 • H 5.49 N 8.68.

1b gave 2b*, crystallized from ethanol, m.p. $187{ }^{\circ} \mathrm{C}$; yield $66 \%$.

* $2 \mathrm{~b}$ could also be obtained from 1 a and $p$-methoxyphenylmagnesium bromide in $58 \%$ yield.

Table I. 2-Cinnamoylbenzimidazole (1 a-e).

\begin{tabular}{|c|c|c|c|c|c|c|c|c|c|c|}
\hline \multirow{3}{*}{ Compound } & \multirow{3}{*}{$\begin{array}{l}\text { m.p. } \\
{\left[{ }^{\circ} \mathrm{C}\right]}\end{array}$} & \multirow{3}{*}{$\begin{array}{l}\text { Yield } \\
{[\%]}\end{array}$} & \multirow{3}{*}{$\begin{array}{l}\text { Solvent } \\
\text { of cryst. }\end{array}$} & \multirow{3}{*}{ Formula } & \multirow{2}{*}{\multicolumn{2}{|c|}{ Carbon }} & \multicolumn{4}{|c|}{ Analysis $[\%]$} \\
\hline & & & & & & & Hydr & ogen & Nity & gen \\
\hline & & & & & Calcd & Found & Calco & Found & Calcd & Found \\
\hline $1 \mathbf{a}$ & 208 & 78 & Ethanol & $\mathrm{C}_{16} \mathrm{H}_{12} \mathrm{~N}_{2} \mathrm{O}$ & 77.39 & 77.15 & 4.88 & 5.02 & 11.28 & 11.03 \\
\hline $1 \mathrm{~b}$ & 195 & 83 & $\mathrm{AcOH}$ & $\mathrm{C}_{17} \mathrm{H}_{14} \mathrm{~N}_{2} \mathrm{O}_{2}$ & 73.35 & 73.23 & 5.08 & 5.28 & 10.06 & 9.88 \\
\hline $1 \mathrm{c}$ & 229 & 86 & $\mathrm{AcOH}$ & $\mathrm{C}_{16} \mathrm{H}_{11} \mathrm{ClN}_{2} \mathrm{O} *$ & 67.96 & 68.24 & 3.93 & 3.91 & 9.91 & 9.70 \\
\hline $1 \mathrm{~d}$ & 244 & 81 & $\mathrm{AcOH}$ & $\mathrm{C}_{16} \mathrm{H}_{11} \mathrm{~N}_{3} \mathrm{O}_{3}$ & 65.51 & 65.39 & 3.79 & 3.98 & 14.33 & 14.28 \\
\hline $1 \mathrm{e}$ & 226 & 72 & Ethanol & $\mathrm{C}_{18} \mathrm{H}_{17} \mathrm{~N}_{3} \mathrm{O}$ & 74.19 & 73.89 & 5.89 & 5.72 & 14.43 & 14.41 \\
\hline
\end{tabular}

* Cl: Calcd 12,53, Found 12.45\%. 
Analysis: $\mathrm{C}_{23} \mathrm{H}_{20} \mathrm{~N}_{2} \mathrm{O}_{2}$

Calcd C 77.49 H 5.66 N 7.86,

Found C 77.31 H 5.54 N 7.98.

Action of Grignard reagents on 2-acylbenzimidazoles

2-Acetylbenzimidazole and 2-benzoylbenzimidazole were reacted with Grignard reagents by the above procedure used for the preparation of $\mathbf{2 a}, \mathbf{b}$. The products $\mathbf{3 a}-\mathbf{e}$ are listed in Table II.

\section{Action of amines on 2-acylbenzimidazoles \\ General procedure}

0.01 Mole of 2-acetylbenzimidazole or 2-benzoylbenzimidazole was heated with 0.015 mole of the amine for 2 hours at $140{ }^{\circ} \mathrm{C}$ (bath temperature). The product was triturated with little ethanol and the solid obtained was filtered off and crystallized from the proper solvent.

4 a was obtained from 2-acetylbenzimidazole and aniline, crystallized from ethanol, m.p. $218^{\circ} \mathrm{C}$; yield $70 \%$.

Analysis: $\mathrm{C}_{15} \mathrm{H}_{13} \mathrm{~N}_{3}$

Calcd C 76.57 H 5.58 N 17.85,

Found C 76.73 H 5.67 N 18.01.

4b was obtained from 2-benzoylbenzimidazole and aniline, crystallized from dilute ethanol, m.p. $181{ }^{\circ} \mathrm{C}$; yield $77 \%$.
Analysis: $\mathrm{C}_{20} \mathrm{H}_{15} \mathrm{~N}_{3}$

$\begin{array}{llll}\text { Calcd } & \text { C } 80.77 & \text { H } 5.09 & \text { N } 14.13 \text {, } \\ \text { Found } & \text { C } 80.60 & \text { H } 4.92 & \text { N } 14.00 .\end{array}$

4c was obtained from 2-benzoylbenzimidazole and $p$-toluidine, crystallized from dilute acetic acid, m.p. $217^{\circ} \mathrm{C}$; yield $83 \%$.

\section{Analysis: $\mathrm{C}_{21} \mathrm{H}_{17} \mathrm{~N}_{3}$ \\ Calcd C 80.99 H $5.51 \quad \mathrm{~N} 13.49$, \\ Found C 81.18 H 5.39 N 13.62.}

\section{Reaction of 1 a with thiourea}

A mixture of 0.01 mole of $\mathbf{1 a}$ and 0.01 mole of thiourea was refluxed in a solution of $2 \mathrm{~g}$ of sodium hydroxide in $100 \mathrm{ml}$ of ethanol and $2 \mathrm{ml}$ of water for 12 hours and then left overnight. The resulting solution was concentrated under vacuum and the solid precipitated was filtered off, washed with little ethanol and dried well. It was crystallized from acetic acid as yellow crystals of 5, m.p. $305^{\circ} \mathrm{C}$, yield $61 \%$.

\section{Analysis: $\mathrm{C}_{17} \mathrm{H}_{14} \mathrm{~N}_{4} \mathrm{~S}$ \\ Calcd C 66.63 H 4.62 N 18.29 S 10.46, \\ Found $\quad$ C $66.82 \quad$ H $4.72 \quad \mathrm{~N} 18.03 \quad$ S 10.44 .}

Table II. 2-(Disubstituted hydroxymethyl)benzimidazole (3a-e).

\begin{tabular}{|c|c|c|c|c|c|c|c|c|c|c|}
\hline \multirow[b]{2}{*}{ Compound } & \multirow{2}{*}{$\begin{array}{l}\text { m.p. } \\
{\left[{ }^{\circ} \mathrm{C}\right]}\end{array}$} & \multirow{2}{*}{$\begin{array}{l}\text { Yield } \\
{[\%]}\end{array}$} & \multirow{2}{*}{$\begin{array}{l}\text { Solvent } \\
\text { of cryst. }\end{array}$} & \multirow[b]{2}{*}{ Formula } & \multicolumn{4}{|c|}{ Analysis [\%] } & \multirow{2}{*}{\multicolumn{2}{|c|}{ Nitrogen }} \\
\hline & & & & & $\begin{array}{l}\text { Cark } \\
\text { Caled }\end{array}$ & Found & $\begin{array}{l}\text { Hydr } \\
\text { Calcd }\end{array}$ & $\begin{array}{l}\text { ogen } \\
\text { Found }\end{array}$ & & \\
\hline $\mathbf{3 a}$ & 218 & 72 & Xylene & $\mathrm{C}_{10} \mathrm{H}_{12} \mathrm{~N}_{2} \mathrm{O}$ & 68.14 & 68.40 & 6.87 & 7.03 & 15.90 & 16.11 \\
\hline $\mathbf{3 b}$ & 196 & 72 & Xylene & $\mathrm{C}_{11} \mathrm{H}_{14} \mathrm{~N}_{2} \mathrm{O}$ & 69.43 & 69.53 & 7.43 & 7.49 & 14.73 & 14.87 \\
\hline $3 \mathrm{c}^{*}$ & 185 & 79 & Ethanol & $\mathrm{C}_{15} \mathrm{H}_{14} \mathrm{~N}_{2} \mathrm{O}$ & 75.59 & 75.74 & 5.92 & 6.13 & 11.76 & 11.90 \\
\hline $3 \mathbf{d}$ & 222 & 76 & Ethanol & $\mathrm{C}_{20} \mathrm{H}_{16} \mathrm{~N}_{2} \mathrm{O}$ & 79.96 & 80.21 & 5.37 & 5.51 & 9.32 & 9.44 \\
\hline $3 \mathbf{e}$ & 220 & 64 & Ethanol & $\mathrm{C}_{21} \mathrm{H}_{18} \mathrm{~N}_{2} \mathrm{O}$ & 80.21 & 80.50 & 5.78 & 5.95 & 8.91 & 9.09 \\
\hline
\end{tabular}

* Prepared by the action of phenylmagnesium bromide on 2 -acetylbenzimidazole, or by the action of methylmagnesium iodide on 2 -benzoylbenzimidazole $(65 \%)$.

1 D. W. Woolley, J. Biol. Chem. 152, 225 [1944].

2 C. H. Roeder and A. R. Day, J. Org. Chem. 6, 25 [1941].

3 W. G. Bywater, W. R. Coleman, O. Kamm, and H. H. Merritt, J. Amer. Chem. Soc. 67, 905 [1945].

4 G. M. VAN DER WANT, Rec. Trav. Chim. 67, 45 [1948].

5 S. P. Grosh, J. Indian Chem. Soc. 28, 710 [1951].

6a N. G. Brink, F. W. Holly, C. H. Shunk, E. W. Peel, J. J. Cahill, and K. Folkers, J. Amer. Chem. Soc. 72, 1866 [1950].

6b F. W. Holly, E. W. Peel, J. J. Cahill, and K. Folkers, ibid. 73, 332 [1951].

6c N. G. Brink and K. Folkers, ibid. 74, 2856 [1952].

7 G. W. H. Cheeseman, J. Chem. Soc. 1964, 4645.
8 M. R. Grimmett, unpublished material, Recent Advances in Heterocyclic Compounds, Ed. A. R. Katritzky, Vol. 12, p. 180, Academic Press, New York 1970.

9 A. Mustafa, M. I. Ali, and A. Abou-State, Liebigs Ann. Chem. 740, 134 [1970].

10 A. Mustafa, W. Asker, A. F. A. Shalaby, and M. E. Sовну, J. Org. Chem. 23, 1992 [1958].

11 A. Bistrzycki and G. Przeworski, Chem. Ber. 45, 3483 [1912].

12 G. E. McCasland, Jr., E. Blanz, and A. Furst, J. Org. Chem. 24, 999 [1959].

13 A. Sammour and M. Elkasaby, J. Chem. UAR 12, 17 [1969].

14 A. Sammour, M. I. B. Selim, M. M. Nour El-Deen, and A. Abd-El-Halim, ibid. 13, 7 [1970]. 